\title{
Experiência Educativa com Grupos de Atenção à Criança em Mariana-MG
}

\author{
An Educational Experience with Childcare \\ Groups in Mariana, Minas Gerais State
}

Fellype Rodrigues Freitas Lopes Adriana Maria de Figueiredo Ana Luiza Leite Costal

Gustavo Ferreira do Nascimento ${ }^{I}$ Lucas Leandro Araújo Silval

Renato Gomes de Souza Nascimento ${ }^{I}$

\section{PALAVRAS-CHAVE: \\ - Saúde da Família; \\ - Saúde da Criança; \\ - Educação em Saúde.}

KEYWORDS:

- Family Health;

- Child Health;

- Health Education.

Recebido em: 20/09/2010

Aprovado em:19/11/2010

REVISTA BRASILEIRA DE EDUCAÇÃO MÉDICA

\section{RESUMO}

Introdução: A educação em saúde é o foco da experiência relatada neste trabalho que foi desenvolvido como uma das atividades de um grupo do Programa de Educação pelo Trabalho para a Saúde (PET-Saúde) da Universidade Federal de Ouro Preto (UFOP) em parceria com a Secretaria Municipal de Saúde de Mariana, no âmbito do Programa de Atenção à Criança do município. Objetivos: Melhorar a interatividade entre profissionais e população por meio de estratégias participativas e lúdicas envolvendo grupos de mães. Métodos: Realização de dinâmicas educativas e avaliativas com os responsáveis pelas crianças e de atividades lúdicas para entretenimento das crianças que são assistidas pelo Programa, ambas pautadas na metodologia da educação popular. Resultados: Os profissionais envolvidos se mostraram receptivos ao uso de novas metodologias educativas no trabalho com aqueles grupos operativos. Os participantes demonstraram interesse e interação nos encontros. As crianças se mostraram satisfeitas em ter um passatempo enquanto aguardavam a avaliação nutricional. O processo proporcionou reflexão crítica e construção de conhecimento entre os monitores e professores. Conclusão: A aproximação entre profissionais de saúde e população, historicamente pautada pela dicotomia entre o saber técnico e o saber popular, é beneficiada por ações que permitem a criação de espaços de diálogo, como os que foram desenvolvidos no grupo com o suporte da metodologia da educação popular.

Introduction: The focus of the experiment discussed here was health education, as one of the activities of a group under the Educational Program for Health Work (PET-Saúde) at the Federal University in Ouro Preto (UFOP) in partnership with the Mariana Municipal Health Department, through the Municipal Childcare Program. Objectives: The objective was to improve interaction between health workers and the population through participatory leisure-time activities involving the children's mothers. Methods: A literature search was conducted to enable the development of group dynamics, with support from the UFOP Educational Toy Collection. Results: Group dynamics were developed, with interactive games and rounds of discussion for evaluation. Conclusion: Collaboration between health workers and the population, traditionally based on the dichotomy between technical expertise and grassroots knowledge, can benefit from actions that take into account the establishment of interfaces for dialogue and exchange of knowledge, such as those introduced by the group with the support of the popular education methodology. 


\section{INTRODUÇÃO}

A educação em saúde é o foco da experiência relatada neste trabalho desenvolvido como uma das atividades de um grupo do Programa de Educação pelo Trabalho para a Saúde (PET-Saúde) da Universidade Federal de Ouro Preto (UFOP) em parceria com a Secretaria Municipal de Saúde de Mariana, no âmbito do Programa de Atenção à Criança do município. $\mathrm{O}$ ponto de vista que orientou o trabalho foi o da construção e utilização de estratégias educativas que trabalhassem o contexto dos envolvidos no processo, tanto o dos profissionais de saúde, quanto o dos participantes do programa.

Nesse sentido, a visão de educação estabelecida para o desenvolvimento do trabalho se refere ao apoio que pode ser construído de forma coletiva pelo grupo em busca de melhorias na qualidade de vida e saúde.

O Programa de Atenção à Criança do município de Mariana atende a crianças na faixa etária de 6 meses a 10 anos de idade. São incluídas no programa as crianças diagnosticadas com desnutrição e cuja renda familiar per capita seja menor ou igual a 1/4 (um quarto) do salário mínimo.

As crianças são acompanhadas mensalmente por uma equipe de saúde composta de uma nutricionista, uma enfermeira, um médico e duas técnicas de enfermagem.

Cada criança permanece no programa por um ano a partir da data de sua inclusão. Após esse período, elas são reavaliadas pelos profissionais e, se necessário, permanecem por mais um tempo, de 4 a 6 meses, recebendo alta após esse período. Se nesse período ainda não tiverem melhorado o seu estado nutricional, os pais/responsáveis são orientados a procurar a Secretaria Municipal de Desenvolvimento Social e Cidadania, para que a família possa ser incluída em outro programa assistencial. As crianças que se recuperam em um tempo menor que um ano, permanecem no programa até esse período seja completo.

Além da avaliação do estado nutricional da criança, também são realizadas, mensalmente, palestras em reuniões de grupos educativos. Os temas abordados vão desde alimentação saudável até doenças mais comuns na infância. Mais precisamente, no período em que foi desenvolvido o trabalho ora apresentado, em outubro e dezembro de 2009, foram abordados, respectivamente, os seguintes temas: "A importância do controle do cartão vacinal" e "Os benefícios que a brincadeira e o entretenimento trazem para o desenvolvimento da criança".

As crianças são divididas em dois grupos: um composto por 48 crianças de 6 meses a 4 anos de idade, e outro com 40 crianças de 5 a 10 anos de idade. Cada grupo é subdividido em três e quatro subgrupos, respectivamente, de modo que cada criança, acompanhada de seu responsável, só vá às reuniões, avaliação e recebimento do alimento uma vez ao mês, ou seja, os subgrupos realizam uma espécie de rodízio semanal controlado pela coordenadora do programa. O primeiro grupo só frequenta às quartas-feiras, enquanto o segundo às segundas-feiras.

A realidade identificada no programa de Atenção à Criança em atividade é a frequência obrigatória das mães às reuniões para o recebimento dos alimentos. Embora não seja possível mensurar o interesse das mães pelas temáticas trabalhadas mensalmente nas palestras realizadas, é possível notar que, como mencionado por Vasconcelos ${ }^{1}$, existia uma distância entre a abordagem que orientava as informações apresentadas pelos profissionais e a recepção destas pelos participantes. As famílias envolvidas no programa compõem um grupo inserido em uma realidade de vulnerabilidade social e merecem uma atenção especial, mais direcionada à realidade que vivenciam. Em decorrência disso, percebeu-se a necessidade de promover uma maior participação por parte das crianças e de seus acompanhantes (pais, mães ou responsáveis) nas palestras, por meio de ações educativas mais próximas de seu contexto e que chamassem mais sua atenção. Assim, a intenção educativa teria maior efetividade se conduzidas por meio de estratégias participativas, que trabalhassem temas de maneira mais interativa, envolvendo todos os presentes, profissionais de saúde e participantes do programa.

Tendo isso em vista, o objetivo foi, então, buscar a integração entre os participantes de modo a aproximar os profissionais de saúde da população envolvida, sem perder de vista a importância do tema a ser discutido para a melhoria da situação de saúde das crianças. Além disso, por meio de realização de dinâmicas de grupo, buscou-se apreender relatos das mães e, dessa forma, procurar entender a realidade na qual elas estão inseridas, de modo a reduzir o distanciamento existente entre a população e os profissionais de saúde envolvidos no programa.

\section{METODOLOGIA}

Os trabalhos foram realizados durante os meses de outubro e novembro de 2009, em encontros semanais que aconteciam às quartas-feiras, quando são acompanhadas as crianças de 6 meses a 4 anos de idade, com o intuito de desenvolver métodos de educação participativa, abrangendo as temáticas propostas para o mês.

Como metodologia de ação, buscou-se a promoção de dinâmicas adaptadas à realidade das famílias e ao tema do mês. No primeiro mês, foram realizadas atividades de apresentação em cada grupo; já no segundo, procurou-se adaptar o tema das dinâmicas ao tema proposto para ser desenvolvido 
durante o mês dos trabalhos. Assim, não houve mais palestras durante o período de realização dos trabalhos. Especificamente para o mês de novembro o tema proposto foi "Os benefícios que a brincadeira e o entretenimento trazem para o desenvolvimento da criança".

Para uma melhor abordagem do assunto, obteve-se um substrato teórico acerca do tema por meio de pesquisas bibliográficas em textos provenientes de distintas áreas do conhecimento - como a Sociologia, a Psicologia; e ainda contou-se com a colaboração de profissionais relacionados com esses campos de conhecimento.

Dessa maneira, concluiu-se que, como diz Winnicott, o brincar é essencial, porque é através dele que se manifesta a criatividade $^{2}$. A partir dessa percepção buscou-se, por meio de um jogo de entrevistas, fazer com que as mães pudessem compreender que as crianças precisavam de um tempo para o entretenimento. Foi realizada, ainda, uma dinâmica de avaliação para averiguação dos resultados do jogo de entrevistas.

Houve o auxílio da Brinquedoteca da UFOP, que enviou uma monitora e brinquedos para que fosse possível realizar os trabalhos com as mães enquanto os filhos tinham um momento de descontração. Segundo Winnicott ${ }^{2}$, crianças de pouca idade ainda permanecem com um forte vínculo materno; assim, elas deveriam permanecer em um local próximo às mães, uma vez que se tratavam de crianças cuja faixa etária estava compreendida entre os 6 meses e 4 anos.

\section{DESENVOLVIMENTO}

No primeiro encontro com o grupo foi realizada uma dinâmica de apresentação, que consistiu em um jogo com base na memorização dos nomes das pessoas que frequentavam as reuniões e em uma discussão acerca do que as pessoas ali presentes julgavam importante para a alimentação das crianças. Foi julgado importante que houvesse a participação dos estudantes de Medicina e dos profissionais envolvidos com o intuito de manter a proximidade com aquelas pessoas, fato que se mostrou essencial para o bom desenvolvimento de uma estratégia educativa.

As dinâmicas realizadas no mês seguinte consistiram em um jogo de entrevistas, o "Programa fala que eu te escuto", em que as mães presentes em cada grupo operativo seriam entrevistadoras em um programa fictício e fariam perguntas às outras mães a respeito da infância delas e da importância da brincadeira para o desenvolvimento da criança, que era o tema a ser trabalhado naquele mês seguindo o cronograma do programa vigente. As perguntas que surgiram com maior frequência foram: "Você brincou com seus pais quando era criança?"; "De que você brincava quando era criança?"; "Você brinca com seus filhos?". Esse jogo de entrevistas serviu como motivação para uma discussão que se seguiu após todas as mães que se dispuseram a participar terem falado. Tal discussão foi necessária para que fosse possível interpretar o que foi dito pelas mães e estabelecer que: "É no brincar, e somente no brincar, que o indivíduo, criança ou adulto, pode ser criativo e utilizar sua personalidade integral: e é somente sendo criativo que o indivíduo descobre o eu (self)" ${ }^{\prime 2}$. A brincadeira sociabiliza e possibilita o desenvolvimento mental, o amadurecimento do indivíduo. Tudo isso foi exposto para aquelas mães de uma forma participativa, em que elas se sentiram à vontade para fazer perguntas e expor experiências próprias. Em seguida, foi realizada uma dinâmica de avaliação para verificar a efetividade do tema trabalhado. Nessa dinâmica, intitulada "Não custa", cada pessoa falaria sobre algo que era muito importante e que foi trabalhado no jogo de entrevistas. Paralelamente a todo o desenvolvimento desses trabalhos, em um mesmo ambiente próximo às mães, permaneceram as crianças brincando com a monitora da Brinquedoteca e os brinquedos levados por ela.

\section{RESULTADOS}

Notou-se que houve receptividade dos profissionais envolvidos para o uso de novas metodologias educativas para trabalho com aqueles grupos operativos. Isso se justifica diante da grande adesão que houve por parte das mães nos trabalhos com novas estratégias educativas e da satisfação das crianças em ter um passatempo enquanto aguardavam a avaliação nutricional.

Para falar de uma atenção integral à saúde da criança, como promoção e produção de saúde e de uma humanização dessas práticas, a equipe de saúde precisa demonstrar percepção e sensibilidade em relação às condutas infantis, e não apenas às rotinas assistenciais (Ceccim,1997). Assim, torna-se necessário repensar estratégias de intervenção que contemplem as necessidades da criança em sua complexidade, vendo-a não apenas como um corpo que precisa de cuidados"3

Percebeu-se no início dos trabalhos com os grupos operativos que, apesar de aquelas mães frequentarem juntas as reuniões há vários meses, elas mal sabiam o nome da pessoa sentada ao lado, o que evidenciou uma imensa falta de integração daqueles grupos. Desse modo, a estratégia de apresentação serviu para o propósito desejado. É necessário ressaltar também a importância da brinquedoteca para que fosse possível realizar o jogo de entrevistas com as mães, dado que era 
fundamental algum meio de entretenimento para as crianças presentes. O contato com textos de cunho psicológico foi interessante no sentido de justificar a estratégia de fazer com que as mães aprendessem sobre a importância do brincar "brincando entre si".

\section{DISCUSSÃO}

Foi percebida a necessidade de priorização do trabalho em equipe. Ações efetivas na promoção da saúde se fundamentam em princípios que primam pelo trabalho multilateral.

\begin{abstract}
Na saúde, também temos uma complexidade para o trabalho em equipe, pois ele implica e envolve necessariamente uma produção. O que é mesmo que se produz nos serviços de saúde? Produzimos algo que não é material, não tem uma forma concreta e interfere diretamente na maneira de viver das pessoas. Esse bem não material tem significados diferentes para diferentes pessoas, em diferentes etapas de suas vidas, em diferentes culturas e momentos da história da humanidade. $\mathrm{O}$ trabalho em saúde produz um bem não material que não se armazena, não é possível deixar saúde guardada nas prateleiras, não é mesmo? E o trabalho em saúde também produz os trabalhadores e a equipe. ${ }^{4}$
\end{abstract}

Observou-se, contudo, que o trabalho em equipe em processos de educação em saúde demanda também a participação dos membros dos grupos nas ações educativas. Dessa forma, ganham importância os grupos operativos em que as metodologias de educação popular, participativa, inovam e aprimoram os princípios do cuidado em saúde.

A narração de que o educador é o sujeito conduz os educandos à memorização mecânica do conteúdo narrado. Mais ainda, a narração os transforma em 'vasilhas', em recipientes a serem 'enchidos' pelo educador. Quanto mais vá 'enchendo' os recipientes com seus 'depósitos', tanto melhor o educador será. Quanto mais se deixem docilmente 'encher', tanto melhores educandos serão.

[...] nesta distorcida visão da educação, não há criatividade, não há transformação, não há saber. Só existe saber na invenção, na reinvenção, na busca inquieta, impaciente, permanente, que os homens fazem o mundo, com o mundo e com os outros. ${ }^{1}$

A realização de trabalhos com crianças desnutridas e seus familiares, ao se pautar no princípio de educação participativa, é capaz de sociabilizar os envolvidos e, de certa forma, trazer um pouco de dignidade a essas pessoas muitas vezes alijadas de uma vida de qualidade. Embora estivesse claro para os integrantes do PET-Saúde que não seria possível influir diretamente na melhoria da qualidade de vida e da situação nutricional das crianças, prevaleceu a expectativa de que estratégias educacionais mais interativas pudessem auxiliar nesse processo.

Sendo assim, recorreu-se à interdisciplinaridade para adequar o trabalho realizado a um tema predefinido pelos profissionais da unidade, o qual seria trabalhado com as mães no mês de novembro - "A importância da brincadeira para o desenvolvimento da criança". Esse tema é apresentado por Deslandes como um recurso terapêutico de promoção à saúde.

A atenção à saúde da criança configura-se como um campo interdisciplinar. Entre as diversas estratégias utilizadas nas ações que envolvem o encontro de diferentes saberes, pode-se situar o brincar. Ele deve ser visto não apenas na perspectiva de recreação, mas como recurso terapêutico que promove, além da continuidade do desenvolvimento infantil, a possibilidade de experiências, funcionando como uma linguagem não verbal de domínio da criança. ${ }^{3}$ (p. 283)

É necessário que haja, cada vez mais, uma incorporação do brincar nas políticas de atenção e nas práticas de assistência à saúde da criança, para que efetivamente se possa, na perspectiva da humanização, transformar os modos de atendimento. Paralelamente aos avanços de saberes específicos e equipamentos voltados para a melhoria no campo da intervenção dirigida a crianças, faz-se necessário desenvolver o campo do conhecimento sobre o brincar como espaço e recurso terapêutico na

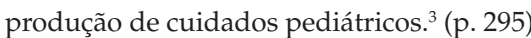

Nesse sentido a incorporação da brincadeira para o contexto da educação em saúde, propiciou aos membros do grupos operativos, a vivência do sentido do brincar. Ao participarem, também eles, de atividades lúdicas, puderam sentir os efeitos que o "brincar" teriam na vida das crianças. Ao mesmo tempo, puderam se dedicar mais ao tema exposto, porque as crianças estavam usufruindo de um espaço próprio para elas, no qual elas não também exerciam o gosto pelo brinquedo.

\section{CONCLUSÃO}

Lidar com pessoas em vulnerabilidade social não é uma tarefa fácil. Uma formação mecanicista, baseada no tratamento do conhecimento como estanques a serem passados à população, dificulta a finalidade primordial dos serviços de saúde, que é 
cuidar de pessoas, de indivíduos em sofrimento, indo além das perspectivas do corpo, compreendendo a vida de cada um e, assim, possibilitar o estabelecimento de estratégias de cura, prevenção, de cuidado em saúde.

\section{REFERÊNCIAS}

1. Vasconcelos EM. Educação popular e a Atenção à Saúde da Família. São Paulo: Hucitec; 2008.

2. Winnicott DW. O brincar e a realidade. Rio de Janeiro: Imago; 1975.

3. Deslandes SF. Humanização dos cuidados em saúde: conceitos, dilemas e práticas. Rio de Janeiro: Ed. Fiocruz; 2008.

4. Fortuna CM. O trabalho de equipe no Programa de Saúde da Família:reflexões a partir de conceitos do processo grupal e de grupos operativos. Rev Latino-Am Enfermagem [periódico na internet]. 2005 [acesso em 28 out. 2009];13(2): [cerca 1 tela]. Disponível em: http://www.revistasusp. sibi.usp.br/scielo.php?script=sci_arttext\&pid=S0104$-11692005000200020 \& \operatorname{lng}=p t \& n r m=$ iso

\section{AGRADECIMENTOS}

Ao participantes dos grupos operativos e à equipe da Unidade de Saúde Previne, no qual foram realizadas as atividades. À preceptora do Programa de Educação pelo Trabalho na Saúde
(PET-Saúde) Adriana Guerra Silva Mattos, que acompanhou o grupo e à Coordenadora do Projeto Brinquedoteca da Universidade Federal de Ouro Preto (UFOP), Roberta Andrade e Barros.

\section{CONTRIBUIÇÃO DOS AUTORES}

Fellype Rodrigues Freitas Lopes, Ana Luiza Leite Costa, Gustavo Ferreira do Nascimento, Lucas Leandro Araújo Silva, Renato Gomes de Souza Nascimento, participaram da revisão da literatura, do planejamento e desenvolvimento das atividades, da elaboração e revisão final do texto. Adriana Maria de Figueiredo participou, como orientadora do trabalho, do planejamento, avaliação e condução das atividades, da elaboração e revisão final do texto.

\section{CONFLITO DE INTERESSES}

Declarou não haver.

\section{ENDEREÇO PARA CORRESPONDÊNCIA}

Fellype Rodrigues Freitas Lopes

Rua Domingues de Bem, 371

Mato Verde

CEP. 39527-000 MG

E-mail: fellype_freitas@hotmail.com 